Dhaka Univ. J. Biol. Sci. 27(1): 9-16, 2018 (January)

\title{
OPTIMIZATION OF HIGH DENSITY LONG DURATION TRANSPORTATION OF SILVER CARP (HYPOPHTHALMICHTHYS MOLITRIX) AND RUI (LABEO ROHITA) FINGERLINGS
}

\author{
MaHmud Hasan \\ Department of Fisheries, University of Dhaka, Dhaka-1000, Bangladesh
}

Key words: Loading density, Transport, Silver carp, Rohu, Bangladesh

\begin{abstract}
The effects of density (50, 55 and $60 \mathrm{~kg}$ fingerlings/drum of 200 litre) on the mortality and essential water quality variables were assessed for silver carp Hypophthalmichthys molitrix fingerlings in a simulated transport experiment. The second experiment involved the determination of the effects of knowing the optimum loading density $50 \mathrm{~kg} /$ drum fingerlings on the mortality and water quality in silver carp advanced fingerlings for standard 8 hours transport simulation. Six hours of simulation duration resulted in less than $1 \%$ mortality and 8 hours caused about $6 \%$. Third experiment with highest density $60 \mathrm{~kg} / \mathrm{drum}$ fingerlings at $500 \mathrm{~g} /$ of advanced rui (Labeo rohita) fingerlings was used for a period of 6 hours since the quality of the transport medium was deteriorated due to regurgitated stomach contents. The fingerlings were unconditioned and fed. Level of immediate mortality was only nearly $3 \%$ at 6 hours of simulation duration. This study has clearly demonstrated that the optimum loading of silver carp fingerlings per drum is $50 \mathrm{~kg}$. The minimum concentration of dissolved oxygen (DO) concentration for maximum survival is $2 \mathrm{mg} /$ for silver carp fingerlings. Silver carp advanced fingerlings can be transported for 8 hours duration by using 2 phenoxyethanol at the concentration of $115 \mu \mathrm{l} / 1$ with oxygen injection. Rui advanced fingerlings can be transported at $60 \mathrm{~kg} / \mathrm{drum}(500 \mathrm{~g} \Lambda)$ for 6 hrs duration even if the fingerlings are unconditioned.
\end{abstract}

\section{Introduction}

Currently nearly $80 \%$ of the carp fingerlings are being transported by road using plastic drums (200 litre) covering a distances of 50 to $600 \mathrm{~km}$ from the seed market or Farmgate to the end users in Bangladesh. Typically, the drums are filled with 130 litre subsurface clean water with 18 (silver carp) - 25 (rohu, catla) kg carp fingerlings. The mouths of the drums are covered with a piece of net to prevent escaping fish from the drum due to violent movement of water. During transportation the fingerlings in each drum are provided with aeration by hand splash by a day laborer. Each truck can be packed with some $10-16$ drums. If necessary the drums are refilled with river or pond

*Author for correspondence: <mhasan@du.ac.bd>. 
water during transportation to cover water lost due to water loss. Mortality of fish fingerlings resulting from handling and transportation was found to be 5-25\%. Sometimes the death tolls may be the entire lot Hasan ${ }^{(1)}$. If this transportation technique is improved, the stocking density may be increased and transportation duration can be extended several-folds, which in turn increase the availability of greater quantity of seed to the end users. Improved transport technique with higher loading density will eventually improve the livelihoods of the carp seed traders by increasing income from higher loading density and reducing loss by improved transportation techniques.

Traditional transport without oxygen supply or mechanical aeration and sedatives results in physical injury, scale loss, fin bifurcation and ultimate deaths of the fingerlings. In addition, without oxygenation or aeration, the transport density, causing increase of transport cost and low income for the seed traders. If the current transport technique can be improved by using compressed oxygen and sedatives, both survival and income can be higher by increasing the stocking density and reducing transport cost per $\mathrm{kg}$ fingerling. This would sustain the development of aquaculture by providing healthy and strong fingerling and steady supply of fish seed to the end users in desired quantity and species on time.

Hasan and Bart(2) have estimated the loss of fish fingerling nearly to be $6200 \mathrm{mt}$ in terms of quantity and Taka 111.60 crore in price resulting from transport mortality. Effects of capture, loading density and transport duration on the growth, survival and stress responses in rui fingerling have been demonstrated by Hasan and Bart ${ }^{(3)}$. Improved survival by using quinaldine and benzocaine with mechanical aeration at a loading density of $400 \mathrm{~g} /$ in silver carp and rui fingerlings have also been demonstrated by Hasan and Bart ${ }^{4}$. However, it is not easy to use aerator in a truck because of no facility currently available to provide energy required for operating aerator. Use of compressed oxygen does not require any energy but provides the most valuable oxygen required for the survival of the fingerlings. Hasan (unpublished data) has determined the efficacy of tertiary amyl alcohol, 2-phenoxyethanol, quinaldine, MS 222 and benzocaine with oxygen supply in the live transportation of silver carp, catla Catla catla and rui fingerlings. Hasan et al.(5,6) has also demonstrated that silver carp, catla and rohu fingerlings at $400 \mathrm{gl}$ can be transported for 6 - $9 \mathrm{hrs}$ with compressed oxygen and anesthetics like TAA, 2 PE, quinaldine and benzocaine. However, the optimum transportation density per 200 litre drum, optimum DO concentration for highest possible survival and optimum PSI of compressed oxygen in the cylinder have never been measured.

The objectives of the present study are to determine the optimum density per drum of silver carp and rui fingerlings for long distance safe transport with oxygen supply and 2 phenoxyethanol sedative optimum dose. 


\section{Materials and Methods}

Experimental fingerlings and procedures: The experimental fingerlings were purchased from Chachra carp seed market. The size of silver carp fingerlings used in the first experiment was $11.52 \pm 1.45 \mathrm{~cm}$ in length and weight $14.97 \pm 5.47 \mathrm{~g}$ (mean $\pm \mathrm{Sd}$ ). In the second experiment, the length and weight of the silver carp advanced fingerlings were $17.19 \pm 0.91 \mathrm{~cm}$ and $48.13 \pm 5.71 \mathrm{~g}$ (mean $\pm \mathrm{Sd}$ ), respectively. The 3rd experiment involved the measurement effects of loading density on the mortality and water quality in rui advanced fingerlings in which the length was $18.64 \pm 2.86 \mathrm{~cm}$ and the weight was $71.75 \pm$ $28.93 \mathrm{~g}$ (mean $\pm \mathrm{Sd}$ ). The fingerlings were purchased from fish seed market, Chachra, Jessore. The purchased fingerlings were unconditioned since conditioned fingerlings were not available at the time of experimental period. After purchase, the fingerlings were held in flow-through-system for overnight except the fingerlings used in the dose response first experiment. The fingerlings were weighed by lifting into the air. While in the first experiment silver carp fingerlings were used as the experimental fish, the second and third experiments used advanced fingerlings as fingerlings were unavailable during the experimental periods. All experiments were conducted at "Ma Fatema Fish Hatchery", Chachra, Jessore in 2014.

Experimental system: The experimental systems were plastic drums of 200 litre capacity and hired from local market of Chachra, Jessore. Subsurface clean water was used as the medium of transport in all three experiments.

Experimental designs: A total three experiments were conducted. The first experiment focused on the determination of optimum loading density and concentration of dissolved oxygen required for long duration safe transport of silver carp fingerlings in a dose response experiment without replicates. In the second experiment, the effects of simulation duration on the mortality and water quality variables were measured in advanced silver carp fingerlings with three replicates by using the optimum loading density ( $50 \mathrm{~kg} / \mathrm{drum}$ ) for 8 hours derived from the first experiment. The third experiment determined the effects of simulation duration on the mortality and water quality variables in advanced rohu fingerlings at the ever highest loading density $60 \mathrm{~kg} / \mathrm{drum}$ at $500 \mathrm{~g} /$ for 6 hrs with three replicates.

The first experiment continued for a period of five hours due to deteriorated water quality problems resulted from regurgitated stomach contents as the fingerlings were not unfed and conditioned. The second experiment was continued for a period of 8 hours as this $8 \mathrm{hrs}$ period is the standard duration required for transporting carp fingerlings from Jessore to Dhaka or other destinations. The 3rd experiment continued for a period of 6 hours, because the water quality deteriorated due to regurgitated stomach contents as the fingerlings were not unfed and conditioned.

Sedative doses: Two phenoxyethanol was used as the sedative in all three experiments. The doses were $115 \mu \mathrm{l} / \mathrm{l}$ for silver carp fingerlings measured earlier by Hasan 
(Unpublished data) and $250 \mu \mathrm{l} /$ for rohu by following Hasan et al.(5). The sedative was purchased from Sigma-Aldrich (Fluca), Germany.

Oxygen: Oxygen cylinders of $9.8 \mathrm{~m}^{3}(99.9 \%$ pure $)$ at 2000 PSI were used as the source of oxygen and released at a very low PSI which was not detectable by using an analog meter. All oxygen cylinders were hired from a local dealer of Bangladesh Oxygen Company (BOC).

Sampling design: Dead fingerlings removed and counted at 1,3 and $5 \mathrm{hrs}$ of simulation duration in silver carp fingerlings in the first experiment, 1, 3, 6 and $8 \mathrm{hrs}$ of simulation duration in silver carp advanced fingerlings in the second experiment and at 1,3 and $6 \mathrm{hrs}$ of simulation duration in rohu fingerlings in the third experiment. Dissolved oxygen concentration and water temperature in the transport drum were also monitored at the time of fingerling sampling.

Water quality variables: Dissolved oxygen concentration and temperature of the transport water were measured by using a portable DO meter ( $\mathrm{HACH}$ sension ${ }^{\mathrm{TM}}$ 6, USA).

Statistical analysis: All per cent data were transformed into square root before statistical analysis. Means were compared by using ANOVA followed by Turkey's HSD post hoc for multiple comparisons. Data were analyzed by using the statistical software SPSS version 20.0 with the level of significance at $p<0.05$.

\section{Results and Discussion}

Experiment 1: Effects of loading density on the mortality and water quality variables in silver carp fingerlings to determine the optimum density.

Mortality rate (\%): No deaths of silver carp fingerlings were found in $50 \mathrm{~kg} / \mathrm{drum}$ loading density until 3 hours of simulation duration (Table 1). Similar results were also observed in the other two treatments (55 and $60 \mathrm{~kg} /$ drum loading densities). However, 5 hours of simulation duration had some mortality across all three density treatments.

Table 1. Loading density response on the immediate mortality in silver carp

Hypophthalmichthys molitrix fingerlings without replicates.

\begin{tabular}{lccc}
\hline \multirow{2}{*}{$\begin{array}{l}\text { Duration } \\
(\mathrm{hr})\end{array}$} & \multicolumn{3}{c}{ Loading density (kg/drum) } \\
\cline { 2 - 4 } & 50 & 55 & 60 \\
\hline 1 & 0.00 & 0.00 & 0.00 \\
3 & 0.00 & 0.00 & 0.00 \\
5 & 2.99 & 3.48 & 2.67 \\
Cumulative & 2.99 & 3.48 & 2.67 \\
\hline
\end{tabular}

The observed no deaths until three hours of simulation duration of silver carp fingerlings across all three loading density treatments indicates the prevalence of suitable 
conditions for survival. However, at $5 \mathrm{hrs}$ of simulation duration the observed little mortality $(<3 \%)$ could have resulted due to deteriorated water quality resulting from regurgitated stomach contents. The color of the water has been found to be changed from clear to greenish and the clearness of the transport medium has been found so bad that the experiment was stopped then. Levels of DO has never been observed below $13 \mathrm{mg} /$ across all three duration treatments in $50 \mathrm{~kg} / \mathrm{drum}$ loading density treatment although 5 hours had some mortality. This clearly denotes that DO did not affect survival. At 5 hours of simulation duration treatment, $60 \mathrm{~kg} /$ drum loading density treatment had even lower mortality than $50 \mathrm{~kg} / \mathrm{drum}$ loading density treatment. This also supports that levels of DO in transport medium were not responsible for the observed little mortality at very high loading density over 5 hrs simulation duration. The observed mortality could be because of no conditioning of the fingerlings Hasan ${ }^{(7)}$. Unconditioned fingerlings could have lost their electrolytes at life threatening level.

DO concentration $(m g / l)$ and water temperature $\left({ }^{\circ} \mathrm{C}\right)$ : Levels of DO never went below 13 $\mathrm{mg} \Lambda$ in $50 \mathrm{~kg} /$ drum loading density (Table 2). In $55 \mathrm{~kg} /$ drum loading density treatment, DO dropped below $6 \mathrm{mg} /$ at 3 hours of simulation and below $3 \mathrm{mg} /$ at 5 hours of simulation duration treatment. In $60 \mathrm{~kg} / \mathrm{drum}$ loading density treatment, levels of DO at 3 and 5 hours of simulation duration treatment were below $2 \mathrm{mg}$. Water temperature over five ours simulation duration did not change much. The maintenance of very high DO levels (>13 mg $/$ ) across all three transport durations in $50 \mathrm{~kg} /$ drum loading density treatment indicates that the pressure at which the pure oxygen has been releasing was

Table 2. Loading density response on the dissolved oxygen (DO) concentration in silver carp Hypophthalmichthys molitrix fingerlings without replicates.

\begin{tabular}{lccc}
\hline Duration & \multicolumn{3}{c}{ Loading density (kg/drum) } \\
\cline { 2 - 4 }$(\mathrm{hr})$ & 50 & 55 & 60 \\
\hline Before loading & 20.46 & 18.96 & 19.03 \\
1 & 17.30 & 11.37 & 6.14 \\
3 & 15.89 & 5.71 & 1.52 \\
5 & 13.60 & 2.89 & 1.79 \\
\hline
\end{tabular}

high enough than the optimum DO ( $5 \mathrm{mg} /$ ) required for tropical fish. The dropped DO at 3 and 5 hours of simulation duration in 55 and $60 \mathrm{~kg} / \mathrm{drum}$ loading density treatments could be due to higher loading densities. Fingerlings could have been stressed more in the later two density treatments than in $50 \mathrm{~kg} / \mathrm{drum}$ treatment. Stressed fingerlings needed greater DO than the less stressed fingerlings. However, levels of DO have been found to decline across all three transport simulation duration treatments in all three density treatments although the pressure of pure oxygen released were same. These declining trends of DO could have been resulted due to increased respiration of the 
fingerlings in the face of deteriorated water quality other than DO and microbial propagation.

Optimum loading density: By considering the DO concentration, $50 \mathrm{~kg} / \mathrm{drum}$ of silver carp fingerlings were considered optimum loading density at $400 \mathrm{~g} /$ since the mortality rate was similar cross all three density treatments.

Minimum concentration of dissolved oxygen required for carp fingerlings' survival: In 60 $\mathrm{kg} /$ drum loading density treatment at 5 hours of simulation duration, level of mortality was even lower than $50 \mathrm{~kg} / \mathrm{drum}$ loading density treatment, the observed DO level nearly $2 \mathrm{mg} /$ (1.79) was considered the minimum level of DO concentration required for the survival of silver carp fingerlings.

Table 3. Loading density response on the water temperature in silver carp

Hypophthalmichthys molitrix fingerlings without replicates.

\begin{tabular}{lccc}
\hline \multirow{2}{*}{$\begin{array}{l}\text { Duration } \\
\text { (hr) }\end{array}$} & \multicolumn{3}{c}{ Loading density (kg/drum) } \\
\cline { 2 - 4 } Before loading & 50 & 55 & 60 \\
1 & 29.60 & 29.50 & 29.50 \\
3 & 29.80 & 29.60 & 29.50 \\
5 & 30.70 & 30.20 & 30.20 \\
\hline
\end{tabular}

Experiment 2: Effects of transport duration (hr) on the mortality and water quality variables in silver carp fingerlings at $50 \mathrm{~kg} / \mathrm{drum}$ loading density.

Mortality rate (\%): No dead fingerlings were detected until $3 \mathrm{hrs}$ of simulation. However, 6 hours had less than $1 \%$ mortality while 8 hrs resulted in nearly $6 \%$ mortality (Table 4). In the second experiment of silver carp fingerlings at $50 \mathrm{~kg} / \mathrm{drum}$ loading density in triplicates, while 6 hours had nearly $1 \%$ mortality, 8 hours has been found to result in nearly $6 \%$ immediate mortality. This observed mortality at 6 and 8 hours of simulation duration treatments were not related to drop DO levels. Because, at 8 hours of simulation duration, the observed level of DO was in excess of $12 \mathrm{mg} /$ which by no means was responsible for fingerling mortality. The mortalities that have been observed at 6 and $8 \mathrm{hrs}$ of simulation duration could be attributable to the no or less conditioning of the fingerlings. The mortality could have also resulted from physical damage of the silver carp advanced fingerlings. The physical damage could have resulted from hand splashing during first phase transport of the fingerlings from nursery of fish seed market at very high loading density. In addition to physical damage, haemolysis of the blood vessels might also responsible for mortality of the fingerlings at a very high DO concentration $(>12 \mathrm{mg} \Lambda)$.

DO concentration $(m g / l)$ and water temperature $\left({ }^{\circ} \mathrm{C}\right)$ : Concentrations of DO never dropped below $5 \mathrm{mg} A$ across all four simulation durations (Table 4). Water temperature 
rose nearly $3^{\circ} \mathrm{C}$ after $6 \mathrm{hrs}$ of simulation and remained as high as over $32^{\circ} \mathrm{C}$ until $8 \mathrm{hrs}$ of simulation duration. Similar to experiment one, the color of the transport water has been found to change from clear to gray-greenish and turbid which could also be due to regurgitated stomach contents. Fingerlings were not stopped feeding and conditioned well for 4 days as opined by Hasan ${ }^{(7)}$.

Table 4. Effects of transport duration (hr) on the mortality and water quality variables in silver carp Hypophthalmichthys molitrix fingerlings with three replicates.

\begin{tabular}{lcccc}
\hline Variables & \multicolumn{4}{c}{ Effects of transport duration $(\mathrm{h})$ on the mortality and water quality } \\
variables \\
\cline { 2 - 5 } & 1 & 3 & 6 & 8 \\
\hline Mortality rate $(\%)$ & $0.00 \pm 0.00$ & $0.00 \pm 0.00$ & $0.75 \pm 0.27^{\mathrm{b}}$ & $5.96 \pm 1.72^{\mathrm{a}}$ \\
DO $(\mathrm{mg} /)$ & $19.30 \pm 1.24^{\mathrm{a}}$ & $5.64 \pm 1.67^{\mathrm{c}}$ & $6.53 \pm 0.95^{\mathrm{c}}$ & $12.55 \pm 0.98^{\mathrm{b}}$ \\
Temperature $\left({ }^{\circ} \mathrm{C}\right)$ & $29.17 \pm 0.35^{\mathrm{b}}$ & $29.93 \pm 0.21^{\mathrm{b}}$ & $32.10 \pm 0.53^{\mathrm{a}}$ & $32.40 \pm 0.21^{\mathrm{a}}$ \\
\hline
\end{tabular}

Loading density was $50 \mathrm{~kg} /$ drum. Means ( $\pm 1 \mathrm{SEM})$ with different letters are significantly different (ANOVA, HSD, p <0.05).

Experiment 3: Effects of transport duration (h) on the mortality and water quality variables in rohu Labeo rohita fingerlings in triplicates.

Mortality rate (\%): Although the loading density was highest in the world (60 $\mathrm{kg} / \mathrm{drum}, 500 \mathrm{~g}$ A), 6 hours simulation duration had only nearly 3\% mortality (Table 5).

Table 5. Effects of transport duration (hr) on the mortality and water quality variables in rohu Labeo rohita fingerlings in triplicates. Loading density was $60 \mathrm{~kg} / \mathrm{drum}$.

\begin{tabular}{lccc}
\hline Variables & \multicolumn{3}{c}{$\begin{array}{c}\text { Effects of transport duration (hr) on the mortality } \\
\text { and water quality variables }\end{array}$} \\
\cline { 2 - 4 } & 1 & 3 & 6 \\
\hline Mortality rate $(\%)$ & $0.00 \pm 0.00$ & $0.08 \pm 0.04$ & $2.79 \pm 0.34$ \\
DO $(\mathrm{mg} A)$ & $9.07 \pm 0.13$ & $13.31 \pm 1.83$ & $2.58 \pm 0.20$ \\
Temperature $\left({ }^{\circ} \mathrm{C}\right)$ & $29.80 \pm 0.17$ & $30.80 \pm 0.29$ & $31.43 \pm 0.13$ \\
\hline
\end{tabular}

Means $( \pm 1$ SEM) with different letters are significantly different (ANOVA, HSD, $p<0.05$ ).

In the third experiment at the ever highest loading density (60 kg/drum, $500 \mathrm{~g} /$ ) treatment of rui fingerlings, the observed nearly 3\% mortality at 6 hours of simulation duration could have resulted due to deteriorated water quality and physical damage. The sources of physical damages are netting, weighing, loading, unloading and hand 
splashing during first phase transport of the fingerlings from nursery to fish seed market.

DO concentration $(m g / l)$ and water temperature $\left({ }^{\circ} \mathrm{C}\right)$ : Levels of DO never went below 2 $\mathrm{mg} \Lambda$. While one hr of simulation duration had nearly $9 \mathrm{mg} \Lambda$ of $\mathrm{DO}$, three hours had over $13 \mathrm{mg} /$ (Table 5). Water temperature ranged between 30 and $31^{\circ} \mathrm{C}$.

The optimum loading density per drum is $50 \mathrm{~kg}$ for silver carp fingerlings with 2 phenoxyethanol at a concentration of $115 \mu \mathrm{l}$ and oxygen injection. Silver carp fingerlings can be transported at $50 \mathrm{~kg} / \mathrm{drum}$ for a period of $8 \mathrm{hrs}$ with little immediate mortality. Silver carp fingerlings can survive at the concentration of dissolved oxygen at $2 \mathrm{mg} /$. Rui advanced fingerlings can be transported as high as $60 \mathrm{~kg} / \mathrm{drum}$ at $500 \mathrm{~g} /$ over a period of 6 hours with 2 phenoxyethanol at the concentration of $250 \mu \mathrm{l} /$ and oxygen injection.

\section{Acknowledgements}

The author thanks the Ministry of Science and Technology, Govt. of the People's Republic of Bangladesh for their financial support to conduct this study (Project ID: BS72/2013-14).

\section{References}

1. Hasan M 2009. Carp seed transport in Bangladesh. Asia-Pacific J. Rural Develop. 19(1): 155-168.

2. Hasan M and AN Bart 2006. Carp seed traders in Bangladesh: Sources of livelihoods and vulnerability resulting from fish seed mortality. Asia-Pacific J. Rural Develop. 16(2): 101124.

3. Hasan M and AN Bart 2007b. Effects of capture, loading density and transport stress on the mortality, physiological responses, bacterial density and growth of rohu Labeo rohita. Fish Physiol. Biochem. 33:241-248.

4. Hasan M and AN Bart 2007a. Improved survival of rohu, Labeo rohita and silver carp, Hypophthalmichthys molitrix fingerlings using low dose quinaldine benzocaine during transport. Aquacult. Res. 38: 50-58.

5. Hasan M, NI Pinky, MA Kabir, S Ahmed and SMM Rashid 2013. Performances of 2 phenoxyethanol, and quinaldine with oxygen in the live truck transportation of rohu fingerlings. J. Asiat. Soc. Bangladesh, Sci. 39(2): 201-209.

6. Hasan M, A Rahman, SMM Rashid and S Ahmed 2014. Effects of tertiary amyl alcohol, 2phenoxyethanol, quinaldine and benzocaine on the mortality and RNA:DNA ratio in catla fingerlings. J. Asiat. Soc. Bangladesh, Sci. 40(1): 121-131.

7. Hasan M 2008. Conditioning improves performance of survival and reduces stress responses in silver carp Hypophthalmichthys molitrix fingerling. Bangladesh J. Zool. 36(1): 59-67.

(Manuscript received on 1 June, 2017; revised on 17 October, 2017) 